Article

\title{
Evaluation of Chemical Strategies for Improving the Stability and Oral Toxicity of Insecticidal Peptides
}

\author{
Volker Herzig ${ }^{1, *}$, Aline Dantas de Araujo ${ }^{1}$, Kathryn P. Greenwood ${ }^{1}$, Yanni K.-Y. Chin ${ }^{1}$, \\ Monique J. Windley ${ }^{2}$, Youmie Chong ${ }^{2}$, Markus Muttenthaler ${ }^{1,3}$, Mehdi Mobli 1,4, \\ Neil Audsley ${ }^{5}$, Graham M. Nicholson ${ }^{2}$, Paul F. Alewood ${ }^{1}$ and Glenn F. King ${ }^{1, *(1)}$
}

1 Institute for Molecular Bioscience, The University of Queensland, St. Lucia, Brisbane QLD 4072, Australia; a.dantasdearaujo@imb.uq.edu.au (A.D.d.A.); kathryngreenwood@hotmail.com (K.P.G.); yanni.chin@imb.uq.edu.au (Y.K.-Y.C.); m.muttenthaler@uq.edu.au (M.M.); m.mobli@uq.edu.au (M.M.); p.alewood@imb.uq.edu.au (P.F.A.)

2 School of Life Sciences, University of Technology Sydney, Broadway, Sydney NSW 2007, Australia; monique.windley@gmail.com (M.J.W.); Youmie.Lawrence@nicnas.gov.au (Y.C.); Graham.Nicholson@uts.edu.au (G.M.N.)

3 Institute of Biological Chemistry, Faculty of Chemistry, University of Vienna, 1090 Vienna, Austria

4 Centre for Advanced Imaging, The University of Queensland, St. Lucia, Brisbane QLD 4072, Australia

5 Food and Environment Research Agency, York YO41 1LZ, UK; Neil.Audsley@fera.co.uk

* Correspondence: v.herzig@uq.edu.au (V.H.); glenn.king@imb.uq.edu.au (G.F.K.); Tel.: +61-7-3346-2018 (V.H.); +61-7-3346-2025 (G.F.K.)

Received: 6 August 2018; Accepted: 23 August 2018; Published: 28 August 2018

\begin{abstract}
Spider venoms are a rich source of insecticidal peptide toxins. Their development as bioinsecticides has, however, been hampered due to concerns about potential lack of stability and oral bioactivity. We therefore systematically evaluated several synthetic strategies to increase the stability and oral potency of the potent insecticidal spider-venom peptide $\omega$-HXTX-Hv1a (Hv1a). Selective chemical replacement of disulfide bridges with diselenide bonds and N- to C-terminal cyclization were anticipated to improve Hvla resistance to proteolytic digestion, and thereby its activity when delivered orally. We found that native Hv1a is orally active in blowflies, but 91-fold less potent than when administered by injection. Introduction of a single diselenide bond had no effect on the susceptibility to scrambling or the oral activity of Hvla. N- to C-terminal cyclization of the peptide backbone did not significantly improve the potency of Hv1a when injected into blowflies and it led to a significant decrease in oral activity. We show that this is likely due to a dramatically reduced rate of translocation of cyclic Hvla across the insect midgut, highlighting the importance of testing bioavailability in addition to toxin stability.
\end{abstract}

Keywords: insecticidal; spider venom peptide; $\omega$-HXTX-Hv1a; oral bioavailability; diselenide bond; cyclization; selenocysteine

\section{Introduction}

Spiders are among the most successful and diverse insect predators on earth. Vital to their evolutionary success has been the evolution of venom to paralyze and kill prey. Venom transforms interactions with prey from a physical battle to chemical warfare, thereby enabling spiders to immobilize prey that are significantly larger than themselves. The number of spider venom peptides has been estimated to exceed 10 million [1], with most assumed to be insecticidal [2]. Thus, spider venoms are a rich source of novel insecticidal compounds [3,4]. Spider venoms have an advantage over synthetic chemical libraries as their component toxins have acquired target selectivity and potency 
during more than 400 million years of co-evolution with their insect prey, and scalable recombinant strategies exist for their production [5].

A potential advantage of spider-venom peptides as leads for bioinsecticides is that most of them contain an inhibitor cystine knot (ICK) [6,7], a structural motif that provides them with high levels of chemical and thermal stability, as well as resistance to proteases $[8,9]$. We recently showed that $\omega$-HXTX-Hv1a (Hv1a), a 37-residue insecticidal peptide from venom of the funnel web spider Hadronyche versuta [7] (Figure 1A), is highly resistant to proteolytic digestion and is stable in organic solvents, highly acidic conditions, and at temperatures up to $75{ }^{\circ} \mathrm{C}$ [10]. Obliteration of the three disulfide bonds in the ICK motif by reduction and alkylation of the cysteine residues significantly reduced the stability of Hv1a under all of these conditions [10]. The stability of ICK peptides can be compromised in biological fluids because endogenous thiol compounds such as glutathione cause reduction and scrambling of disulfide bonds [11]. Loss of disulfide-bond integrity compromises the $3 \mathrm{D}$ fold of the peptide and enhances its susceptibility to proteolytic degradation.
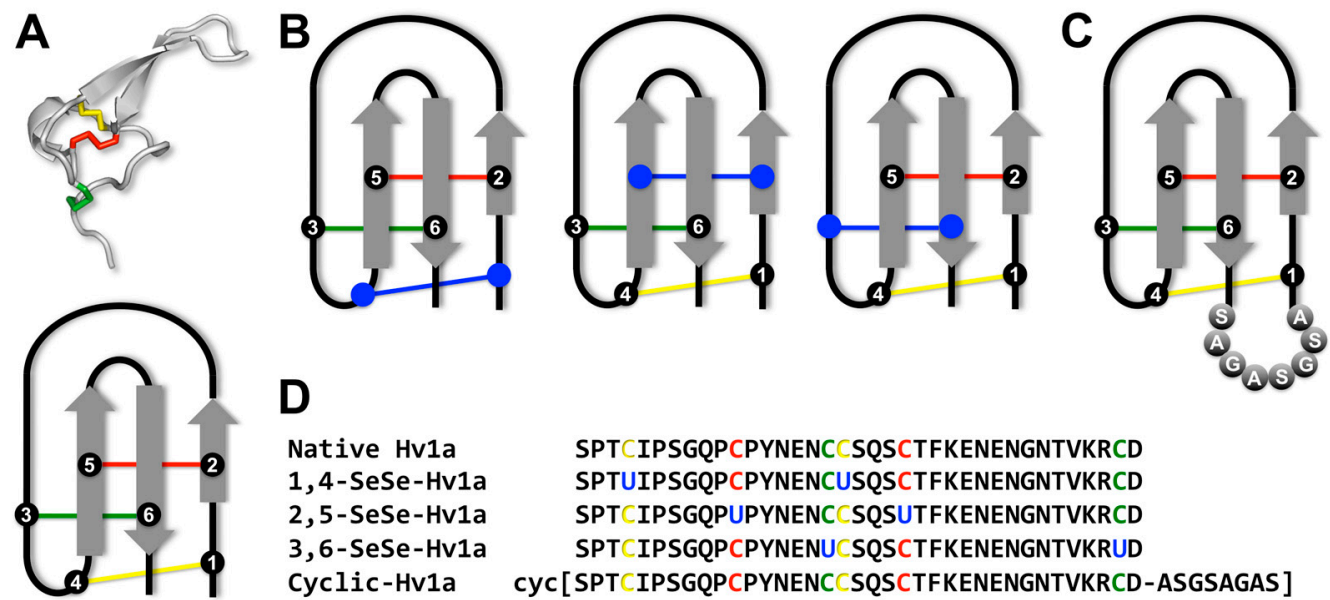

D

Native Hv1a 1,4-SeSe-Hv1a 2,5-SeSe-Hv1a 3,6-SeSe-Hv1a Cyclic-Hv1a
SPT CIPSGQPCPYNENC SQSCTFKENENGNTVKRCD SPTUIPSGQPCPYNENCUSQSCTFKENENGNTVKRCD SPT IPSGQPUPYNENC SQSUTFKENENGNTVKRCD SPT IPSGQPCPYNENU SQSCTFKENENGNTVKRUD CYC[SPT IPSGQPCPYNENC SQSCTFKENENGNTVKRCD-ASGSAGAS]

Figure 1. Sequence and structure of Hvla and analogs with the colors indicating individual disulfide bonds (C1-C4 = yellow; C2-C5 = red and C3-C6 = green) (A) Top panel: Three-dimensional structure of native Hv1a (PDB 1AXH; [7]). Bottom panel: Schematic of the inhibitor cystine knot (ICK) motif of Hv1a, which comprises an antiparallel $\beta$-sheet (shown in grey) stabilized by a cystine knot. The six cysteine residues that form the cystine knot are labelled 1-6; (B) Schematic of the ICK motif for the three diselenide analogs of Hv1a. The blue color indicates replacement of a disulfide bond with a diselenide bond; (C) Schematic of the ICK motif for the cyclic Hv1a analog. The eight residues that form the linker bridging the N- and C-termini are labelled; (D) Amino acid sequences of native Hv1a and the various analogs used in this study.

Another concern for development of spider-venom peptides as insecticides is their presumed lack of oral activity. Since spiders inject venom directly into their prey, there is no evolutionary pressure to develop toxins with oral activity [12]. Nevertheless, we recently discovered a peptide from venom of the Australian tarantula Selenotypus plumipes that has potent oral activity against the cotton bollworm Helicoverpa armigera [13]. Furthermore, the toxicity of Hv1a to Amblyomma americanum ticks is only marginally lower when delivered per os compared to when it is injected into these arthropods [14]. Hv1a is also presumed to be orally active to lepidopteran insects as transgenic tobacco plants expressing Hv1a are toxic to H. armigera and the cotton leafworm Spodoptera littoralis [15]. Finally, it was recently shown that $>70 \%$ of spider venoms are orally active to Drosophila melanogaster [16].

Replacement of disulfide bonds with diselenide bonds, as well as $\mathrm{N}$ - to C-terminal cyclization, are established chemical methods for improving peptide stability and oral activity. Cyclization has, for example, been used to enhance the stability and oral activity of disulfide-rich conotoxins $[17,18]$. 
Diselenide analogs of conotoxins and spider toxins have been reported that exhibit increased stability, selectivity or potency on their molecular target $[11,19,20]$.

In this study, we examined the oral insecticidal activity of Hv1a and evaluated two methods designed to improve its intrinsic oral activity: replacement of disulfide bonds with diselenide bonds and cyclization of the peptide backbone (Figure 1B-D). We show that native Hv1a has oral activity, albeit 91-fold lower than by injection. Individual replacement of any of the three disulfide bonds in Hv1a with a diselenide bond did not improve its oral activity. Surprisingly, cyclization of Hv1a reduced its oral potency, and we demonstrate that this is likely due to a reduced translocation rate across the insect midgut.

\section{Results}

\subsection{Synthesis of Diselenide and Cyclic Analogs of Hv1a}

Although selenocysteine is isosteric with cysteine, diselenide bonds have a much lower redox potential than disulfide bonds [21] and are therefore less prone to reductive shuffling [22]. For example, the half-life of the cone snail peptide $\alpha$-conotoxin ImI in human plasma was greatly enhanced when one or both of the disulfide bridges were replaced with diselenide bonds as the extent of disulfide shuffling was reduced [11]. Substituting disulfides with diselenides in peptides bearing multiple disulfide bridges can also yield improvements in folding, activity, and receptor selectivity [11,19,23-26]. Cyclization of the peptide backbone has also been found to increase resistance to proteases while maintaining biological activity and three-dimensional structure [27,28]. Cyclization can even improve receptor selectivity $[17,29]$ or facilitate folding of certain isomers [30]. Thus, we examined whether the stability and oral activity of Hvla could be enhanced by backbone cyclization or by substituting the native disulfide bonds with diselenides (Figure 1B,D).

Synthetic Hv1a was produced without difficulty using SPPS (Figure 2A); the mass after oxidative folding (4048.9 Da) matched well with the theoretical mass (4049.4 Da). After SPPS assembly, cleavage of 1,4-SeSe-Hv1a from resin yielded one major product (theoretical reduced mass $4145.5 \mathrm{Da}$; observed reduced mass, $4145.6 \mathrm{Da}$ ), which was purified and subjected to oxidative folding. The quality and quantity of crude material obtained for this analog was comparable to that obtained for native Hv1a, and there was a slight increase in overall folding efficiency (Figure 2B; Table 1), as previously observed for folding of other diselenide-containing peptides [24,25]. The identity of the fully oxidised 1,4-SeSe-Hv1a was confirmed using ESI-MS (observed mass 4140.8 Da; theoretical mass 4141.5 Da).

In contrast to 1,4-SeSe-Hv1a, synthesis of the 2,5-SeSe-Hv1a and 3,6-SeSe-Hv1a analogs was more problematic. It was necessary to treat the post-cleavage products with a reducing reagent (DTT) to improve yields of the desired reduced diselenide intermediate. Diselenide formation at positions 2,5and 3,6-appears to be less favoured than the 1,4-diselenide, which leads to some Se-S bond formation. Unwanted linkages in the 2,5-peptide could be substantially reversed by DTT treatment to restore the Se-Se bonds, but this was only partially effective for the 3,6-peptide. Oxidative folding of both analogs was less efficient than native Hv1a (Figure 2C,D; Table 1).

Table 1. Accumulation of correctly folded toxin during folding and susceptibility of the native and diselenide Hv1a to scrambling.

\begin{tabular}{cccc}
\hline \multirow{2}{*}{ Peptide } & \multirow{2}{*}{ Folding Efficiency } & \multicolumn{2}{c}{ Correctly Folded Toxin } \\
\cline { 3 - 4 } & & With 1 Equivalent GSH, pH 7.2 & In Buffer, pH 7.2 \\
\hline native Hv1a & $48 \%$ & $85 \%$ & $100 \%$ \\
1,4-SeSe-Hv1a & $55 \%$ & $85 \%$ & $100 \%$ \\
2,5-SeSe-Hv1a & $38 \%$ & $82 \%$ & $100 \%$ \\
3,6-SeSe-Hv1a & $27 \%$ & $60 \%$ & $95 \%$ \\
\hline
\end{tabular}




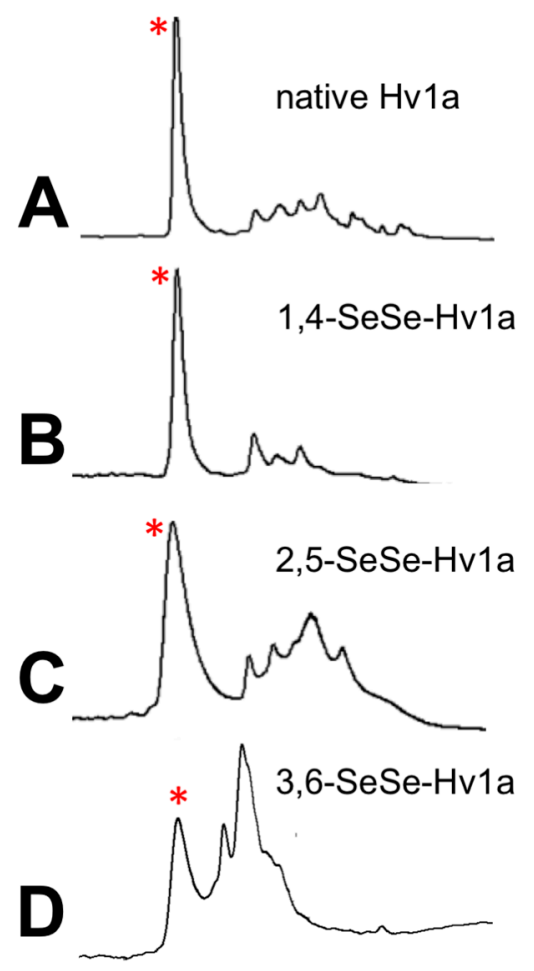

Figure 2. Oxidative folding of native and diselenide analogs of Hv1a. (A-D): RP-high-performance liquid chromatography (HPLC) chromatograms showing the native and each of the diselenide analogs of Hv1a after oxidative folding. The folding conditions were: $0.2 \mathrm{M}$ MOPS buffer, $\mathrm{pH} 7.3,0.4 \mathrm{M}$ $\mathrm{KCl}, 2 \mathrm{mM}$ EDTA, $10 \mathrm{mM}$ GSH/2 mM GSSG, 24 h, room temperature. Asterisks denote the peak corresponding to the correctly folded diselenide toxin.

\subsection{Synthesis of Cyclic Hv1a}

A linear version of Hv1a containing an 8-residue linker (Figure 1C,D) and a C-terminal thioester was prepared using SPPS, cleaved from the resin, and purified to $>95 \%$ purity as assessed by analytical RP-HPLC and ESI-MS (theoretical mass $4789.00 \mathrm{Da}$, observed mass $4790.36 \mathrm{Da}$ ). Cyclization was achieved by native chemical ligation in a redox buffer that simultaneously cyclized and oxidised the linear peptide. Following oxidative folding, the oxidized cyclic Hv1a theoretical mass was $4620 \mathrm{Da}$ and observed reduced mass was $4619.68 \mathrm{Da}$. Cyclization efficiency was $\sim 85 \%$.

The percentage of correctly folded toxin was determined in neutral media and in the presence of GSH. As shown in Table 1, native Hv1a, 1,4-SeSe-Hv1a and 2,5-SeSe-Hv1a were only weakly prone to scrambling in the presence of GSH, whereas 3,6-SeSe-Hv1a was more susceptible to scrambling. Surprisingly, this analog also exhibited marginal instability in neutral media for $24 \mathrm{~h}$.

\subsection{Structural Comparison of Native and Cyclic Hv1a}

The chemical shifts of the backbone amide $\left(\mathrm{H}_{\mathrm{N}}\right)$ and $\mathrm{C} \alpha$ protons $(\mathrm{H} \alpha)$ of a peptide are highly sensitive to peptide conformation and they are routinely used to monitor whether mutations in a peptide induce structural perturbations. Thus, we used a combination of $2 \mathrm{D}^{1} \mathrm{H}-{ }^{1} \mathrm{H}$ TOCSY and ${ }^{1} \mathrm{H}-{ }^{1} \mathrm{H}$ NOESY spectra of cyclic Hv1a to sequence-specifically assign $89 \%$ of the $\mathrm{H}_{\mathrm{N}}$ and $91 \%$ of $\mathrm{H} \alpha$ protons, then we compared these chemical shifts to those previously reported for native Hv1a (BMRB file 6192) [7] (Figure 3). The similarity in $\mathrm{H}_{\mathrm{N}}$ and $\mathrm{H} \alpha$ shifts for native and cyclic Hv1a indicate that they adopt a similar conformation. Thus, any observed difference in activity between the cyclic and native peptides is not due to structural perturbations caused by peptide cyclization. 

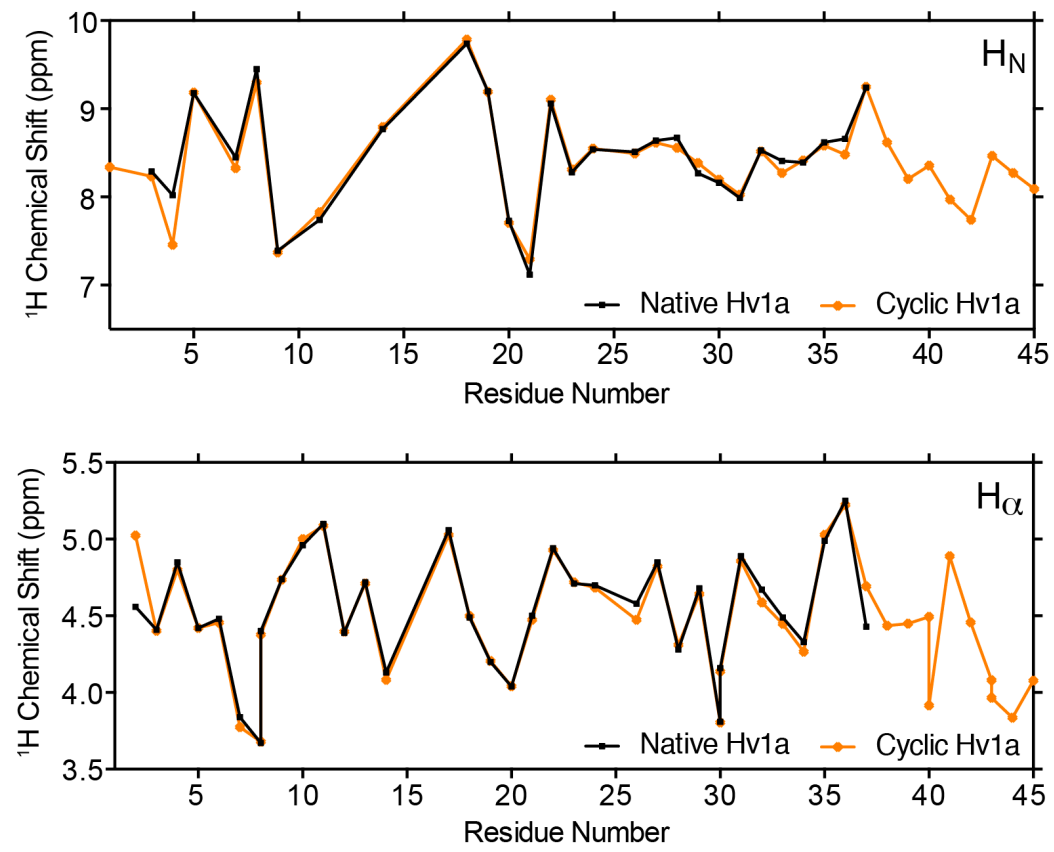

Figure 3. Comparison of the $\mathrm{H}_{\mathrm{N}}$ (top) and $\mathrm{H} \alpha$ chemical shifts (bottom) of cyclic and native Hv1a.

\subsection{Blowfly Toxicity Assays}

The intrinsic insecticidal activity of Hv1a and the diselenide and cyclic analogs was determined by injection of the peptides into sheep blowflies. Calculation of $\mathrm{LD}_{50}$ values from the resultant dose-response curves (Table 2) indicated that none of the analogs have significantly different insecticidal activity to native Hv1a ( $p>0.05$, using a Kruskal Wallis test followed by Dunn's multiple comparisons test). Thus, substitution of disulfide bonds with diselenide bonds or backbone cyclization neither impaired nor enhanced the insecticidal activity of Hv1a.

Table 2. $\mathrm{LD}_{50}$ values for injection of Hv1a and analogs into sheep blowflies.

\begin{tabular}{cccccc}
\hline Toxin & $\boldsymbol{\omega}$-Hv1a & 1,4-SeSe- $\boldsymbol{\omega}$-Hv1a & 2,5-SeSe- $\boldsymbol{\omega}$-Hv1a & 3,6-SeSe- $\boldsymbol{\omega}$-Hv1a & Cyclic- $\boldsymbol{\omega}$-Hv1a \\
\hline $\mathrm{LD}_{50}(\mathrm{pmol} / \mathrm{g})$ & $499 \pm 53$ & $407 \pm 22$ & $455 \pm 35$ & $446 \pm 12$ & $293 \pm 18$ \\
\hline
\end{tabular}

The oral activity of Hv1a and the diselenide and cyclic analogs was determined by feeding the peptides to sheep blowflies. Although full dose-response curves could not be determined due to limited amounts of material (Figure 4), the data are sufficient to conclude that all of the analogs have reduced oral activity compared to native Hv1a.

\subsection{Electrophysiology}

We used patch-clamp electrophysiology to examine the effects of 1,4-SeSe-Hv1a and cyclic $\omega$-Hv1a on medium/low-voltage-activated (M-LVA) and high-voltage-activated (HVA) Cav channels in cockroach DUM neurons. We used a peptide concentration of $278 \mathrm{nM}$ as this was previously shown to be the $\mathrm{IC}_{50}$ for inhibition of M-LVA Cav channels by native Hv1a [31]. In comparison to native Hv1a, the 1,4-SeSe-Hv1a and cyclic Hv1a analogs induced similar inhibition of both M-LVA and HVA $\mathrm{Ca}$ channel currents (Figure 5A,B). The degree of inhibition by either analog was not significantly different to that of native Hv1a (two-way ANOVA, $p>0.05, n=3-5$; Figure 5C). As for native Hv1a, neither analog significantly altered the voltage-dependence of $\mathrm{Ca}_{\mathrm{V}}$ channel activation (Figure 5D,E). 


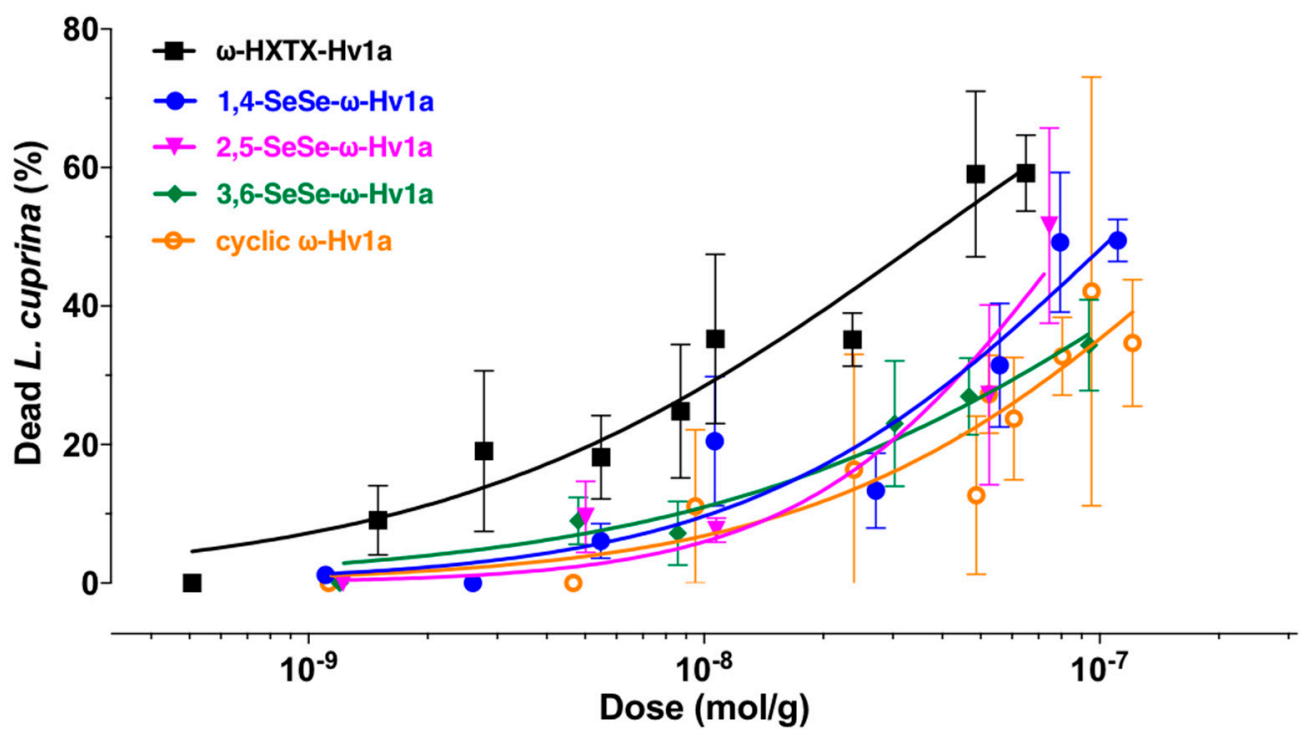

Figure 4. Oral toxicity assays. Lethality was determined $24 \mathrm{~h}$ after oral ingestion of toxin by sheep blowflies. All of the analogs have decreased oral activity compared to native Hv1a.

\subsection{Midgut Permeation Assay}

We used flat-sheet preparations of the anterior midgut of Manduca sexta mounted in an Ussing chamber to measure the transepithelial (i.e., lumen to hemolymph) flux of native Hv1a and analogs over a $60 \mathrm{~min}$ period (Table 3). The flux of native toxin was concentration dependent, with the highest flux of $351 \pm 32 \mathrm{pmol} / \mathrm{cm}^{2} / \mathrm{h}$ recorded when $10 \mu \mathrm{M}$ toxin was present on the luminal side. The fluxes of native Hv1a, at a dose of $10 \mu \mathrm{M}$, measured on separate occasions using different batches of M. sexta, were not significantly different (unpaired $t$-test, $p=0.18$ ).

Table 3. In vitro lumen to hemolymph flux of Hvla and analogs across the midgut of Manduca sexta larvae when present at different concentrations in the luminal fluid. Data are mean \pm S.E.M, $n=9-19$.

\begin{tabular}{cccc}
\hline \multirow{2}{*}{ Concentration of Hv1a or Analog $(\boldsymbol{\mu M})$} & \multicolumn{3}{c}{ Lumen to Hemolymph Flux $\left(\mathbf{p m o l} / \mathbf{c m}^{\mathbf{2}} / \mathbf{h}\right)$} \\
\cline { 2 - 4 } & Hv1a & Cyclic Hv1a & 1,4-SeSe-Hv1a \\
\hline 0.1 & $11.8 \pm 2.7$ & $0.14 \pm 0.03$ & - \\
1.0 & $41 \pm 11$ & $1.7 \pm 0.6$ & - \\
10 & $351 \pm 32$ & $94 \pm 16$ & - \\
10 & $287 \pm 23$ & - & $227 \pm 14$ \\
\hline
\end{tabular}

The lumen to hemolymph flux of cyclic Hv1a was also dose-dependent, but these fluxes were significantly lower than those of the native toxin at all three concentrations tested $(0.1,1$, and $10 \mu \mathrm{M}$; unpaired Student's $t$-test, $p<0.0001 ; p=0.0026 ; p=0.0006$, respectively). Similarly, at a concentration of $10 \mu \mathrm{M}$ in the lumen saline, the lumen to hemolymph flux of 1,4-SeSe-Hv1a was significantly less than that of the native Hv1a (unpaired Student's $t$-test, $p=0.0322$ ).

We confirmed that the peptide toxins were being transported intact across the midgut membrane by MALDI-TOF MS analysis of fluid from the hemolymph side of the chamber. 

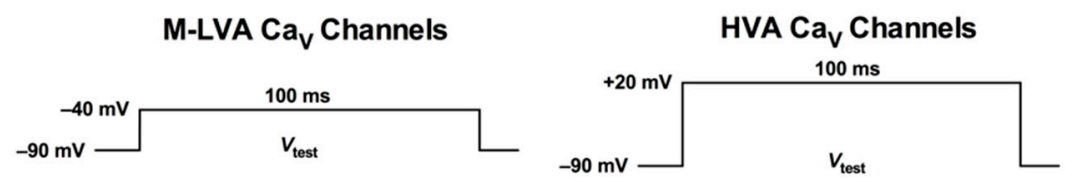

Aa

Ab
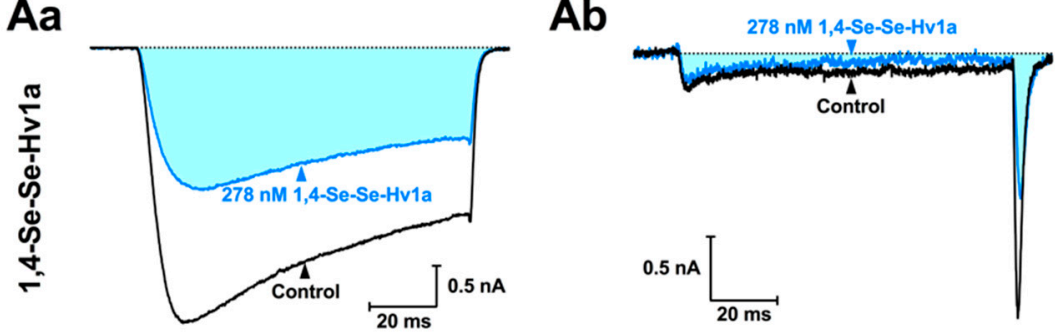

$\mathrm{Ba}$

$\mathrm{Bb}$
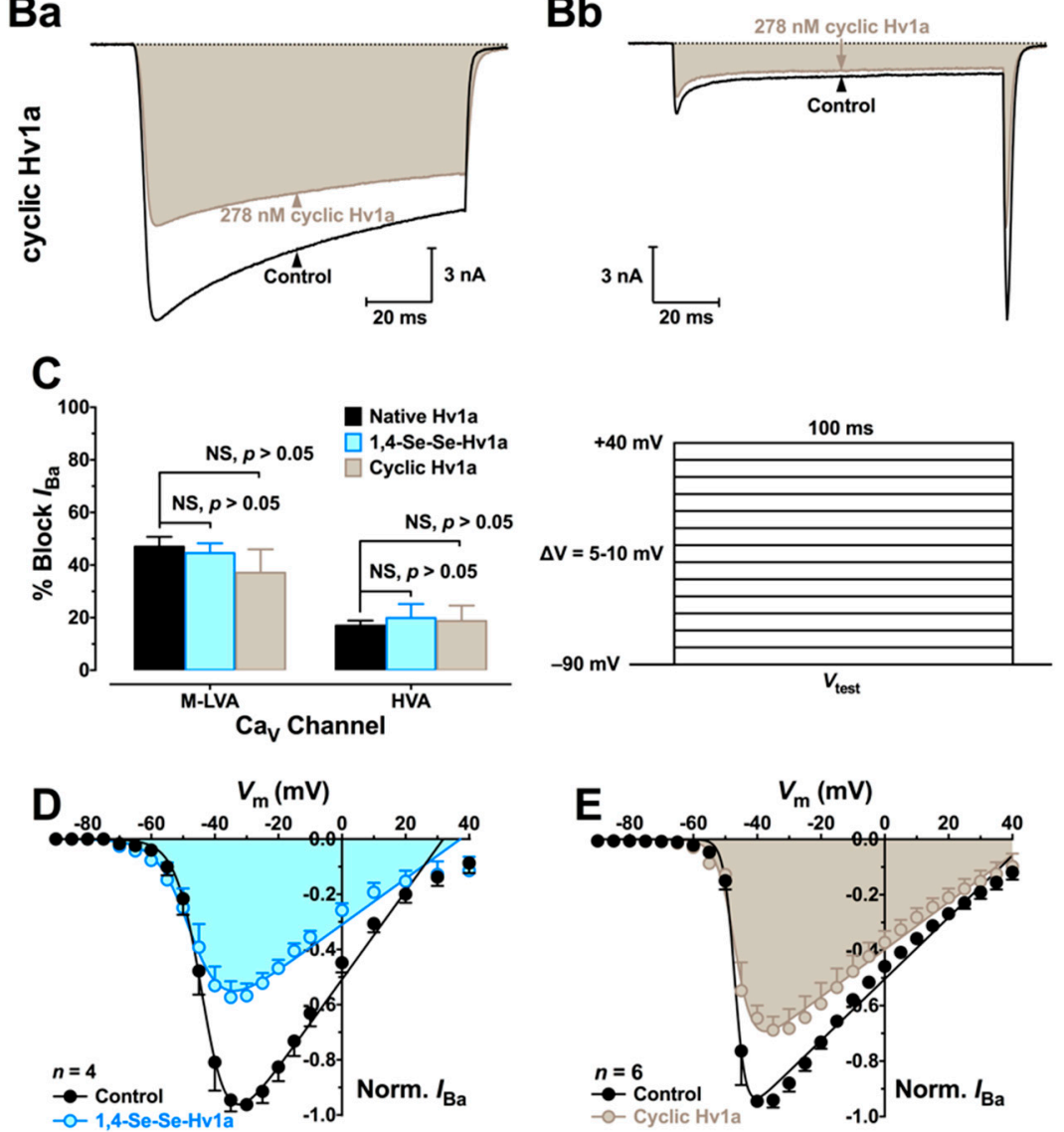

Figure 5. Effect of Hvla and analogs on $\mathrm{Ca}_{\mathrm{V}}$ channels in cockroach dorsal unpaired median (DUM) neurons. (A,B) Typical effects of (A) 1,4-SeSe-Hv1a and (B) cyclic Hv1a on $I_{\text {Ba. Representative control }}$ (black) and toxin (cyan and shaded for 1,4-Se-Se-Hv1a, grey and shaded for cyclic Hv1a) traces elicited by a $100-\mathrm{ms}$ depolarising test pulse ( $\left.V_{\text {test }}\right)$ to $-40 \mathrm{mV}$ (left-hand 'a' panels; M-LVA Ca $\mathrm{V}$ channel currents) or $+20 \mathrm{mV}$ (right-hand ' $\mathbf{b}$ ' panels; HVA CaV channel currents). The dotted line represents zero current. Voltage protocols are shown above traces; (C) Comparison of average block of M-LVA and HVA $I_{\mathrm{Ba}}$ by native Hv1a (black), 1,4-SeSe-Hv1a (cyan), and cyclic Hv1a (gray). Data are mean \pm SEM ( $n=4-5)$. There were no significant differences between native Hv1a and either analog (two-way ANOVA, $p>0.05, n=3-5)$; (D,E) Effect of (D) 1,4-SeSe-Hv1a and (E) cyclic Hv1a (E) on the voltage-dependence of $\mathrm{Ca}_{\mathrm{V}}$ channel activation. $\mathrm{Ca}_{\mathrm{V}}$ channel currents were elicited by the pulse protocol shown above panel (E); Currents recorded in the presence of toxin were normalised to the maximum inward $I_{\mathrm{Ba}}$ in controls and fitted with Equation (1) (see Section 4.5). Data shows normalised $I_{\mathrm{Ba}}$ before (closed circles) and after (open circles and shaded) application of toxin. Data are mean $\pm \operatorname{SEM}(n=4-5)$. 


\section{Discussion}

The primary methods of delivering bioinsecticides to target insects is foliar spraying or the use of genetically engineered plants that express insecticidal toxins [32]. Thus, it is essential for new bioinsecticides to be orally toxic to insects. However, upon oral administration to insects, neurotoxic venom peptides such as Hv1a are subject to reduction and proteolytic degradation in the midgut and hemolymph before reaching their ion channel targets in the central or peripheral nervous system. Thus, using Hv1a as a model bioinsecticide, we interrogated different strategies for increasing peptide stability and oral availability. The first strategy aimed to reduce the susceptibility of Hv1a to reduction in the insect midgut and hemolymph by selectively replacing each of the three disulfide bonds with diselenide bonds (Figure 1B). The second strategy aimed to increase the resistance of the toxin to degradation by exoproteases via head-to-tail cyclization (Figure 1C). To determine whether either of these strategies for increasing peptide stability also increased oral activity, we examined the oral toxicity of native Hv1a and the various analogs in sheep blowflies (Lucilia cuprina), a common pest of Australian livestock [33].

Native Hv1a was potently insecticidal when injected into sheep blowflies, with a $\mathrm{LD}_{50}$ ( $500 \mathrm{pmol} / \mathrm{g})$ that is only slightly higher than the most potent insecticidal spider-venom peptides tested in this assay [20,34,35]. A key finding of this study is that Hv1a is also orally active in blowflies, with an oral $\mathrm{LD}_{50}$ that is 91 -fold higher than the $\mathrm{LD}_{50}$ obtained by injection. This is considerably better than the ratio of 714 obtained for the oral vs. injection $\mathrm{LD}_{50}$ of the scorpion toxin AaIT in Sarcophaga flesh flies [36], and only 2-fold lower than the factor of 45 observed for the cardiotoxic fraction $\mathrm{D}_{3}$ from venom of the South African cobra Naja mossambica mossambica in Sarcophaga [37]. Furthermore, the 91-fold difference in $\mathrm{LD}_{50}$ values obtained for Hv1a is very similar to the factor of 93 obtained for the oral vs. injection activity of the insecticidal spider-venom peptide OAIP-1 in mealworms (larvae of Tenebrio molitor) [13]. Overall, these literature values together with the present data show that some peptide toxins can be orally active in insects, although the doses required for oral activity are significantly higher than those required to produce the same effect by injection. Nevertheless, with an oral $\mathrm{LD}_{50}$ of $\sim 45 \mathrm{nmol} / \mathrm{g}$, Hv1a can be considered a potent orally active bioinsecticide.

Replacement of the 1,4-disulfide bond in Hv1a with a diselenide bond did not affect the toxin's folding efficacy or its inhibitory activity on insect $\mathrm{Ca}_{\mathrm{V}}$ channels. Moreover, by injection, the 1,4-SeSe-Hv1a analog was marginally more toxic to blowflies than native Hv1a. Replacement of either the 2,5- or 3,6-disulfide bond with a diselenide bond reduced folding efficacy, but these chemical modifications did not impact the intrinsic potency of the toxin, as the $\mathrm{LD}_{50}$ for injection of these analogs into blowflies was very similar to that of native Hv1a (Table 2). We conclude that replacement of individual disulfide bonds with diselenide bonds does not impact on the toxin's activity on insect $\mathrm{Ca}_{\mathrm{V}}$ channels or its in vivo activity by injection. In contrast, head-to-tail cyclization of Hv1a did not affect its ability to inhibit insect $\mathrm{Ca}_{\mathrm{V}}$ channels, but it did improve the toxin's intrinsic insecticidal potency when injected into blowflies, presumably as a result of enhanced in vivo stability. This would be consistent with previous studies showing increases in peptide stability as a result of backbone cyclization $[27,28]$.

Surprisingly, all of the chemical modifications examined in this study reduced the oral activity of Hv1a. The insecticidal potency of an orally ingested peptide neurotoxin will depend on a number of factors including: (i) Intrinsic potency on its target, which for Hv1a is $\mathrm{Ca}_{\mathrm{V}}$ channels located in the central nervous system [38]; (ii) stability in insect gut and hemolymph; (iii) ability to penetrate the midgut epithelium to gain entry to the hemolymph; (iv) ability to breach the blood-brain barrier to access centrally located $\mathrm{Ca}_{V}$ channels. Neither backbone cyclization nor disulfide-to-diselenide transformations affected the intrinsic potency of Hv1a on insect $\mathrm{Ca}_{\mathrm{V}}$ channels. Moreover, none of these chemical modifications affected the $\mathrm{LD}_{50}$ of injected toxin, indicating that they do not affect its stability in hemolymph or its ability to penetrate the blood-brain barrier. We therefore suspected that the lower oral activity of these analogs might be due to reduced penetrance of the insect midgut. Indeed, we found that cyclization of Hv1a dramatically reduced its ability to traverse the midgut of 
the lepidopteran Mandaca sexta. Introduction of a diselenide bond in the 1,4-SeSe-Hv1a analog also led to a slight reduction in midgut penetration.

The mechanism underlying decreased midgut permeation of the cyclic analog remains unclear. Several peptides and proteins have been shown to traverse the insect gut [39], although the factors that influence their rate of transport are not well studied. Amphiphilic analogs of insect neuropeptides show enhanced oral availability, which has been explained by their ability to cross the foregut with its cuticular component, thereby avoiding the peptidase-rich environment in the midgut [40]. There is also some evidence of paracellular transport of proteins [41,42] and peptides [39,43] through the insect midgut. Leaky septate junctions in insect midgut might explain the paracellular transport of small peptides $(<5 \mathrm{kDa})$ [32]. If Hv1a crosses the midgut via the paracellular route, then the small increase in size due to the eight-residue linker in the cyclic Hv1a would not be sufficient to explain its decreased permeation rate. Moreover, Hv1a is about 5-fold larger than the insect neuropeptide cydiastatin, but the midgut permeation rate of Hv1a is more than 42-times higher than of cydiastatin. Thus, variations in peptide size are not sufficient to explain their very different propensities to cross the insect midgut epithelium. Another possible explanation for the reduced midgut permeation of the cyclic analog could be that the polar serine residues in the linker, which were introduced to ensure peptide solubility in the hemolymph, negatively impacted on the toxin's potential to traverse the midgut epithelium. Thus, in future experiments, it would be informative to examine the impact of varying the polarity of the linker residues on the ability of cyclic Hvla to penetrate the insect midgut.

Interestingly, the 3,6-SeSe-Hvla analog was less stable in the presence of both GSH and neutral media, which might explain why its oral toxicity is significantly lower than native Hv1a. In the ICK motif, the 3,6-disulfide bond projects through the loop formed by the other two disulfide bonds, thereby forming a pseudo-knot. The 3,6-disulfide is closely packed against the two other disulfides that surround it, and therefore replacing the sulfur atom with a slightly larger selenium atom might have caused minor structural disturbances that affect the peptide's stability.

\section{Experimental Section}

\subsection{Peptide Synthesis}

\subsubsection{Chemicals}

$N^{\alpha}$-Boc-L-amino acids, 4-methylbenzhydrylamine (MBHA) resin, and reagents used during chain assembly were purchased from Novabiochem (Merck, Kilsyth, Victoria, Australia). $N^{\alpha}$-Boc-L-amino acid-phenylacetamidomethyl (PAM)-resin was from Peptides International (Louisville, KY, USA), 2-(1H-benzotriazol-1-yl)-1,1,3,3-tetramethyluronium hexafluoro-phosphate (HBTU) was from Fluka (Buchs, Switzerland), while $N, N^{\prime}$-diiso-propylethylamine (DIEA), trifluoroacetic acid (TFA), dichloromethane (DCM), and $N, N^{\prime}$-dimethylformamide (DMF) were from Auspep (Melbourne, VIC, Australia). Anhydrous hydrogen fluoride (HF) was from BOC Gases (Sydney, NSW, Australia), while $p$-cresol and $p$-thiocresol, as well as all other organic reagents and solvents, unless stated otherwise, were from Sigma-Aldrich (Sydney, NSW, Australia). All solvents for solid phase peptide synthesis (SPPS) were peptide-synthesis grade and used without further purification. High-performance liquid chromatography (HPLC)-grade acetonitrile (Lab Scan, Bangkok, Thailand) and MilliQ water (ELGA, Melbourne, VIC, Australia) were used to prepare all HPLC solvents.

\subsubsection{Synthesis of Native Hv1a and Diselenide Analogs}

Native Hv1a and diselenide analogs were synthesized manually by Boc SSPS using the in situ neutralization protocol $[24,44]$. Synthesis was carried out on a $0.25 \mathrm{mmol}$ scale using MBHA resin. Boc-L-Sec(MeBzl)-OH [11] was used to incorporate selenocysteine (Sec, U) residues during assembly of [C4U,C18U]-Hv1a (1,4-[Se-Se]-Hv1a), [C11U,C22U]-Hv1a (2,5-[Se-Se]-Hv1a) and [C17U,C36U]-Hv1a (3,6-[Se-Se]-Hv1a). After HF cleavage in HF:p-cresol (9:1) at $0{ }^{\circ} \mathrm{C}$ for $1.5 \mathrm{~h}$ (see [45] for further details), 
crude 1,4-SeSe-Hv1a was purified by preparative RP-HPLC using a Vydac C18 column and a linear gradient of $5-30 \%$ solvent B $(0.043 \%$ TFA, $90 \%$ acetonitrile $(\mathrm{ACN}))$ in solvent A $(0.05 \%$ TFA in water) over $60 \mathrm{~min}$. The crude 2,5- and 3,6-SeSe-Hv1a products were first treated with dithiothreitol (DTT) for $2 \mathrm{~h}$ (peptide dissolved at $1 \mathrm{mg} / \mathrm{mL}$ in $100 \mathrm{mM}$ DTT in $0.1 \mathrm{M}$ phosphate buffer, $\mathrm{pH}$ 4) and then purified using RP-HPLC. All three selenopeptides were folded in a redox buffer (0.1 M MOPS pH 7.3, 0.2 M $\mathrm{KCl}, 1 \mathrm{mM}$ EDTA, $2 \mathrm{mM}$ reduced glutathione (GSH), $0.2 \mathrm{mM}$ oxidised glutathione (GSSG)) for $24 \mathrm{~h}$ at a peptide concentration of at $0.1 \mathrm{mg} / \mathrm{mL}$. The folding reaction was quenched with TFA, then the folded seleno-Hv1a analogs were purified using RP-HPLC (Vydac C18 column, linear gradient of 0-20\% solvent B over $50 \mathrm{~min}$ ) and the expected mass confirmed using electrospray ionisation mass spectrometry (ESI-MS).

\subsubsection{Synthesis of Cyclic Hv1a}

Hv1a was cyclized by connecting the $\mathrm{N}$ - and C-termini via an eight-residue peptide linker (ASGSAGAS). The length of this linker, which bridges a gap of $13 \AA$ in the native toxin [7], was based on the seven-residue linker that was used to successfully bridge the $11.2 \AA$ gap between $N$ - and C-termini of $\alpha$-conotoxin MII [27]. Amino acids with short side chains were selected for the linker to minimise potential structural perturbations, serine was used periodically to improve hydrophilicity, and amino acids were alternated to simplify NMR analysis of the peptide.

Hv1a was cyclized using a native chemical ligation approach [46] as described previously [27]. S-trityl- $\beta$-mercaptopropionic acid was coupled to PAM-resin followed by assembly of the sequence CSQSCTFKENENGNTVKRCD-ASGSAGAS-SPTCIPSGQPCPYNENC by Boc-SPPS, with the residues in bold corresponding to the linker. The thioester peptide was cleaved from the resin in HF: $p$-cresol (9:1) at $0^{\circ} \mathrm{C}$ for $1.5 \mathrm{~h}$, then purified by RP-HPLC using a Phenomenex C18 preparative column and a linear gradient of $0-60 \%$ solvent B in solvent A over 60 min. Peptide masses were determined using ESI-MS.

Backbone cyclization was performed using intramolecular native chemical ligation in solution [46]. Cys18, which was chosen as the required N-terminal cysteine residue, was cyclized to the generated Cys17 thioester. The purified reduced peptide was folded and cyclized at $20.9 \mu \mathrm{M}$ concentration in a redox buffer at room temperature (0.02 M MOPS pH 7.3, 0.04 M KCl, 0.2 mM EDTA, 0.4 mM GSH, $0.1 \mathrm{mM}$ GSSH). The reaction was quenched with TFA after $16 \mathrm{~h}$. Cyclic Hv1a was purified to $>95 \%$ purity via RP-HPLC using a Phenomenex C18 semi-preparative column and a linear gradient of 0-40\% solvent B over 40 min. Peptide masses were determined using ESI-MS.

\subsection{Suceptibility to Scrambling of Hv1a Diselenide Analogs}

Peptide $(45 \mu \mathrm{L}$ of a $250 \mu \mathrm{M}$ solution) was combined with either $45 \mu \mathrm{L}$ of buffer $(0.1 \mathrm{M}$ phosphate buffer, pH 7.2) or $45 \mu \mathrm{L}$ of buffer containing $250 \mu \mathrm{M}$ GSH. After $24 \mathrm{~h}$, the reaction was quenched with $1 \%$ TFA and the solution analysed using analytical RP-HPLC.

\subsection{NMR Spectroscopy and Resonance Assignments of Cyclic Hv1a}

$2 \mathrm{D}^{1} \mathrm{H}$ NMR spectra of cyclic Hv1a (1.3 mM in 93\% $\left.\mathrm{H}_{2} \mathrm{O}, 7 \% \mathrm{D}_{2} \mathrm{O}, \mathrm{pH} 3.25\right)$ were acquired at $25^{\circ} \mathrm{C}$ on a cryoprobe-equipped Avance III spectrometer (Bruker BioSpin, Ettlingen, Germany) operating at $900 \mathrm{MHz}$. Resonance assignments were made using 2D TOCSY (mixing time $80 \mathrm{~ms}$ ) and 2D NOESY spectra (mixing time $200 \mathrm{~ms}$ ) using the programs SPARKY [47] and CCPnmr [48]. Backbone $\mathrm{H}_{\mathrm{N}}$ and $\mathrm{H} \alpha$ chemical shifts were compared to those reported for native Hv1a at pH 3.6 (BMRB Entry 6192).

\subsection{Blowfly Toxicity Assay}

Injection assays using sheep blowflies (Lucilia cuprina) were performed as described [49]. Briefly, peptides were dissolved in insect-saline and injected into the ventro-lateral thoracic region of blowflies (mass 16.5-27.0 mg). Thereafter, flies were individually housed in $2 \mathrm{~mL}$ tubes and lethality determined after $24 \mathrm{~h}$. 
Tests for oral toxicity in blowflies were performed as described [16]. In short, peptides were dissolved in 5\% sucrose and $3 \mu \mathrm{L}$ of this solution was applied to the inside of a $2 \mathrm{~mL}$ tube containing a single fly (mass 16.8-25.3 mg). Flies were kept in the tube overnight without additional food or water until the sucrose solution was consumed. Thereafter, flies were transferred into $250 \mathrm{~mL}$ plastic containers and provided with a sugar cube and wet cotton wool. Each box housed 10 flies that received the same treatment. Oral toxicity was determined three days after the oral application. For both injection and oral toxicity assays, three tests were carried for each peptide, and for each test several doses of peptide ( $n=10$ flies per dose) were used along with appropriate controls (i.e., insect saline or $5 \%$ sucrose solution; $n=20-40$ ). $\mathrm{LD}_{50}$ values were calculated as described previously [50].

\subsection{Electrophysiology}

Dorsal unpaired median (DUM) neurons were isolated from unsexed adult American cockroaches (Periplaneta americana), as described in [31]. Briefly, terminal abdominal ganglia were removed into sterile $\mathrm{Ca}^{2+} / \mathrm{Mg}^{2+}$-free insect saline (in mM: $200 \mathrm{NaCl}, 3.1 \mathrm{KCl}, 10 \mathrm{~N}$-2-hydroxyethylpiperazine- $\mathrm{N}$-2-ethanesulfonic acid (HEPES), 60 sucrose). Ganglia were then desheathed and incubated for $15 \mathrm{~min}$ at $37{ }^{\circ} \mathrm{C}$ in $\mathrm{Ca}^{2+} / \mathrm{Mg}^{2+}$-free insect saline containing collagenase $(1 \mathrm{mg} / \mathrm{mL})$ and hyaluronidase $(1 \mathrm{mg} / \mathrm{mL})$. The ganglia were then centrifuged and rinsed three times in normal insect saline (in mM: $200 \mathrm{NaCl}, 3.1 \mathrm{KCl}, 5 \mathrm{CaCl}_{2}, 4 \mathrm{MgCl}_{2}, 10$ HEPES, 50 sucrose) supplemented with bovine calf serum $(5 \% v / v)$, penicillin $(50 \mathrm{IU} / \mathrm{mL})$, and streptomycin $(50 \mathrm{mg} / \mathrm{mL}$ ) (Trace Biosciences, Noble Park, VIC, Australia). DUM neurons were then mechanically isolated from exogenous tissue by trituration through a fire-polished Pasteur pipette. The resultant cell suspension was then distributed onto 12-mm diameter glass coverslips pre-coated with $1 \mathrm{mg} / \mathrm{mL}$ concanavalin A (type IV) or Cell-Tak (BD Biosciences, Sydney, Australia). Isolated cells were allowed to attach to the coverslips overnight in an incubator, then maintained at $28{ }^{\circ} \mathrm{C}, 100 \%$ humidity for $12-24 \mathrm{~h}$.

Voltage-clamp recordings of calcium channel currents were made from DUM neurons using the whole-cell patch-clamp technique. Due to current rundown when calcium is used as the charge carrier [51], $\mathrm{BaCl}_{2}$ replaced $\mathrm{CaCl}_{2}$ in all experiments. Recordings of $I_{\mathrm{Ba}}$ were made with fire-polished borosilicate macropipettes of $2-3 \mathrm{M} \Omega$ resistance when filled with an internal pipette solution containing, in mM: 10 sodium acetate, $110 \mathrm{CsCl}, 50$ tetraethylammonium (TEA)- $\mathrm{Br}, 2 \mathrm{ATP}-\mathrm{Na}_{2}, 0.5 \mathrm{CaCl}_{2}$, 10 EGTA, 10 HEPES, pH 7.3. The external solution for recording $I_{\mathrm{Ba}}$ contained, in mM: 160 sodium acetate, 30 TEA-Br, $3 \mathrm{BaCl}_{2}, 10$ HEPES, $\mathrm{pH}$ 7.4. The osmolarity of both solutions was adjusted to $420-430 \mathrm{mOsm} / \mathrm{L}$ with sucrose to reduce osmotic stress. The external solution was applied at a flow rate of $0.5-1 \mathrm{~mL} / \mathrm{min}$. Data were recorded at room temperature $\left(20-23^{\circ} \mathrm{C}\right)$. The liquid junction potential between internal and external solutions was determined using the program JPCalc [52], and all data compensated for this value. Stimulation and recording were controlled with pClamp v9 or v10 data acquisition software (Molecular Devices, San Jose, CA, USA). Data were filtered at $5 \mathrm{kHz}$ (four-pole lowpass Bessel filter) and the digitally sampled at $20 \mathrm{kHz}$. Leakage and capacitive currents were digitally subtracted with $P-P / 4$ procedures [53] and series resistance compensation was set at $>80 \%$ for all cells. Neurons were voltage clamped at $-90 \mathrm{mV}$, and currents evoked by stepping the membrane potential from -90 to $+40 \mathrm{mV}$. $\mathrm{Cd}^{2+}(500 \mu \mathrm{M})$ was used to abolish $I_{\mathrm{Ba}}$ and confirm that recorded currents were from insect $\mathrm{Ca}_{\mathrm{V}}$ channels [54].

Off-line data analysis was performed using Axograph X v1.3 (Molecular Devices) or Clampfit 10 (Molecular Devices). Voltage-activation relationships were obtained by measuring steady-state currents elicited by stepwise depolarizations of $5-10 \mathrm{mV}$ from a holding potential of $-90 \mathrm{mV}$. Current-voltage $(I / V)$ curves were fitted using the equation:

$$
I_{\text {Ba }}=\left[1+\exp \left(-0.03937 z\left(V_{\mathrm{m}}-V_{1 / 2}\right)\right)\right]^{-1} g\left(V_{\mathrm{m}}-V_{\text {rev }}\right)
$$


where $z$ is the apparent gating charge, $g$ is a factor related to the number of channels contributing to the macroscopic whole-cell $I_{\mathrm{Ba}}, V_{\mathrm{m}}$ is the voltage potential of the pulse, and $V_{1 / 2}$ is the voltage at half-maximal activation [55].

Dose-response curves were fitted with the following logistic equation to determine $\mathrm{IC}_{50}$ values:

$$
y=1 /\left(1+[x] / \mathrm{IC}_{50}\right)^{n \mathrm{H}}
$$

where $x$ is the toxin dose, $n_{\mathrm{H}}$ is the Hill coefficient (slope parameter), and $\mathrm{IC}_{50}$ is the median inhibitory concentration for block of $I_{\mathrm{Ba}}$.

Mathematical curve fitting and statistical analyses were accomplished using GraphPad Prism (GraphPad Software, San Diego, CA, USA). All curve-fitting routines were performed using non-linear least squares regression. Comparisons of two sample means were made using a paired Student's $t$-test and differences were considered to be significant if $p<0.05$. All data are presented as mean \pm standard error of mean (SEM) for $n$ independent experiments.

\subsection{Midgut Permeation Assay}

Flat-sheet preparations of the anterior midgut of Manduca sexta were mounted in Ussing-type chambers as previously described [39]. The lumen to hemolymph flux was determined by applying various concentrations of peptide $(0.1,1$, and $10 \mu \mathrm{M})$ to the luminal side of the tissue and taking aliquots of saline from the hemolymph side after $1 \mathrm{~h}$ incubation at $30^{\circ} \mathrm{C}(n=9-19$ tissues per peptide and dose). 1,4-SeSe-Hv1a was compared to native Hv1a at $10 \mu \mathrm{M}$ on the lumen side of the tissue ( $n=11-12$ tissues). Due to difficulties in synthesising sufficient amounts of peptide, the 2,5 and 3,6-SeSe-Hvla analogs were not tested in this assay. To check for damage to gut tissues that would allow leakage of peptides through the tissues, $1 \%$ amaranth, which is not absorbed across gut epithelia, was added to the luminal side of the tissue. Samples were analysed using a combination of liquid chromatography, enzyme-linked immunosorbent assay (ELISA), and matrix-assisted laser desorption/ionisation time-of-flight mass spectrometry (MALDI-TOF MS) to quantify the amount of intact peptide present on the hemolymph side of the tissue [39].

Chromatography was performed using a Beckman System Gold chromatographic system (Beckman Coulter Ltd., High Wycombe, UK) consisting of a dual pump programmable solvent module 126 and System Gold UV detector module 166. Samples were loaded onto a Jupiter $C_{18}$ analytical column $(10 \mu \mathrm{m}, 300 \AA, 2.1 \times 250 \mathrm{~mm})$ fitted with a guard column $(2.1 \times 30 \mathrm{~mm})$ of similar packing material (Phenomenex, Macclesfield, UK). Samples were eluted using a linear gradient of $10-60 \% \mathrm{ACN} / 0.1 \%$ TFA over $50 \mathrm{~min}$ at a flow rate of $0.2 \mathrm{~mL} / \mathrm{min}$, and elution monitored at $214 \mathrm{~nm}$. Fractions $(0.2 \mathrm{~mL})$ were collected and dried by centrifugal evaporation. An indirect ELISA was used to measure immunoreactivity in HPLC fractions corresponding to the elution position of intact peptide, using methods reported previously [56]. Briefly, HPLC fractions and synthetic peptide were dried onto multi-well plates (Sigma-Aldrich, Gillingham, UK; cat. No. M4034) at $37^{\circ} \mathrm{C}$, then incubated overnight at $4{ }^{\circ} \mathrm{C}$ with $100 \mathrm{~mL}$ of $0.1 \mathrm{M}$ bicarbonate (coating) buffer ( $\mathrm{pH}$ 9.6). Plates were washed three times with $150 \mathrm{~mL}$ of $10 \mathrm{mM}$ phosphate buffer/0.1\% TWEEN-20 (PBS), then blocking solution (150 mL; 2\% non-fat milk in PBS) was added and the plates were incubated for $90 \mathrm{~min}$ at $37^{\circ} \mathrm{C}$. After a further PBS wash $(3 \times), 100 \mathrm{~mL}$ of primary Hv1a antiserum (dilutions 1:10,000 to detect Hv1a; 1:2000 for SeSe-Hv1a) was added to each well and plates were incubated for a further $90 \mathrm{~min}$ at $37^{\circ} \mathrm{C}$. Goat anti-rabbit antiserum conjugated with horseradish peroxidase (100 mL; 1:3000 dilution in PBS) was added as secondary antibody to each well after PBS washes $(3 \times)$. Plates were then incubated for $40 \mathrm{~min}$ at $37^{\circ} \mathrm{C}$. After final PBS washes $(3 \times), 100 \mathrm{~mL}$ of substrate solution $(25 \mathrm{mg}$ O-phenylenediamine, $20 \mathrm{~mL} \mathrm{H}_{2} \mathrm{O}_{2}$ in $25 \mathrm{~mL}$ citrate buffer, $\mathrm{pH}$ 5.0) were added to each well, and the plates incubated for $40 \mathrm{~min}$ at $37^{\circ} \mathrm{C}$. The reaction was stopped by addition of $50 \mathrm{~mL} 1.0 \mathrm{M} \mathrm{H}_{2} \mathrm{SO}_{4}$ to each well, then optical density at $492 \mathrm{~nm}$ was measured using a Labsystems Multiskan MCC/340 microplate reader (Thermo 
Electron Corporation, Basingstoke, UK). Absorbance was converted to peptide concentration using standard curves.

MALDI-TOF MS was also used to analyse fluid from the hemolymph side of the chamber. MALDI-TOF MS spectra were obtained using a Voyager DE mass spectrometer (Applied Biosystems, Warrington, UK) using sinapinic acid $(10 \mathrm{mg} / \mathrm{mL}$ in $30 \% \mathrm{ACN} / 0.05 \% \mathrm{TFA})$ as matrix. Dried samples were resuspended in $10 \mu \mathrm{L} 70 \% \mathrm{ACN}$, then $0.5 \mu \mathrm{L}$ was added to the MALDI-TOF sample plate together with $0.5 \mu \mathrm{L}$ matrix before drying at room temperature. The mass spectrometer was calibrated using oxidised insulin B chain, adrenocorticotropic hormone clip 7-38, bovine insulin, and oxidised thioredoxin standards. Spectra are the accumulation of $3 \times 50$ shots in positive linear mode, and reported masses are for the monoisotopic $[\mathrm{M}+\mathrm{H}]^{+}$ions.

\section{Conclusions}

In summary, we showed that Hvla can traverse the insect midgut epithelium and is orally active in insects. Replacement of individual disulfide bonds with diselenide bonds, or cyclization of the peptide backbone, did not affect the ability of the toxin to inhibit insect $\mathrm{Ca}_{\mathrm{V}}$ channels but both of these chemical modifications decreased the oral activity of the peptide. In the case of the cyclic peptide, the lower oral activity appears to be due to a markedly decreased ability to breach the insect gut epithelium. Further research will be required to determine whether head-to-tail cyclization has similar negative impacts on the oral activity of other insecticidal venom peptides.

Author Contributions: Conceptualization, V.H., A.D.d.A., K.P.G., G.M.N., P.F.A. and G.F.K.; Formal analysis, V.H., A.D.d.A., K.P.G., N.A., G.M.N. and G.F.K.; Investigation, V.H., A.D.d.A., K.P.G., Y.K.-Y.C., M.J.W., Y.C., M.M. (Mehdi Mobli) and N.A.; Resources, N.A., G.M.N., P.F.A. and G.F.K.; Writing-original draft, V.H., A.D.d.A., K.P.G., Y.K.-Y.C., M.M. (Markus Muttenthaler), G.M.N. and G.F.K.

Funding: This work was supported by the Australian Research Council (Discovery Grants DP0774245 to G.F.K. and DP0878450 to G.F.K. and P.F.A., and DECRA Fellowship DE150100784 to M.M. (Markus Muttenthaler)), the Australian National Health \& Medical Research Council (Principal Research Fellowships to G.F.K. and P.F.A.), and the European Research Council under the European Union's Horizon 2020 research and innovation programme (Grant agreement No. 714366 to M.M. (Markus Muttenthaler)).

Acknowledgments: We thank Geoff Brown (Queensland Department of Agriculture and Fisheries) for supplying blowfly larvae.

Conflicts of Interest: The authors declare no conflict of interest.

\section{References}

1. Escoubas, P.; Sollod, B.; King, G.F. Venom landscapes: Mining the complexity of spider venoms via a combined cDNA and mass spectrometric approach. Toxicon 2006, 47, 650-663. [CrossRef] [PubMed]

2. Herzig, V.; King, G.F. Spider toxins and their potential for insect control. In Insect Pharmacology; Gilbert, L.I., Gill, S.S., Eds.; Elsevier: Oxford, UK, 2010; pp. 119-123.

3. King, G.F.; Hardy, M.C. Spider-venom peptides: Structure, pharmacology, and potential for control of insect pests. Annu. Rev. Entomol. 2013, 58, 475-496. [CrossRef] [PubMed]

4. Windley, M.J.; Herzig, V.; Dziemborowicz, S.A.; Hardy, M.C.; King, G.F.; Nicholson, G.M. Spider-venom peptides as bioinsecticides. Toxins 2012, 4, 191-227. [CrossRef] [PubMed]

5. Klint, J.K.; Senff, S.; Saez, N.J.; Seshadri, R.; Lau, H.Y.; Bende, N.S.; Undheim, E.A.; Rash, L.D.; Mobli, M.; King, G.F. Production of recombinant disulfide-rich venom peptides for structural and functional analysis via expression in the periplasm of E. coli. PLOS ONE 2013, 8, e63865. [CrossRef] [PubMed]

6. Pallaghy, P.K.; Nielsen, K.J.; Craik, D.J.; Norton, R.S. A common structural motif incorporating a cystine knot and a triple-stranded $\beta$-sheet in toxic and inhibitory polypeptides. Protein Sci. 1994, 3, 1833-1839. [CrossRef] [PubMed]

7. Fletcher, J.I.; Smith, R.; O’Donoghue, S.I.; Nilges, M.; Connor, M.; Howden, M.E.; Christie, M.J.; King, G.F. The structure of a novel insecticidal neurotoxin, $\omega$-atracotoxin-HV1, from the venom of an Australian funnel web spider. Nat. Struct. Biol. 1997, 4, 559-566. [CrossRef] [PubMed] 
8. Saez, N.J.; Senff, S.; Jensen, J.E.; Er, S.Y.; Herzig, V.; Rash, L.D.; King, G.F. Spider-venom peptides as therapeutics. Toxins 2010, 2, 2851-2871. [CrossRef] [PubMed]

9. Craik, D.J.; Daly, N.L.; Waine, C. The cystine knot motif in toxins and implications for drug design. Toxicon 2001, 39, 43-60. [CrossRef]

10. Herzig, V.; King, G.F. The cystine knot is responsible for the exceptional stability of the insecticidal spider toxin $\omega$-hexatoxin-Hv1a. Toxins 2015, 7, 4366-4380. [CrossRef] [PubMed]

11. Armishaw, C.J.; Daly, N.L.; Nevin, S.T.; Adams, D.J.; Craik, D.J.; Alewood, P.F. $\alpha$-Selenoconotoxins, a new class of potent $\alpha 7$ neuronal nicotinic receptor antagonists. J. Biol. Chem. 2006, 281, 14136-14143. [CrossRef] [PubMed]

12. Nentwig, W. Spider venoms are not suitable insecticides. Toxicon 1993, 31, 233-236. [CrossRef]

13. Hardy, M.C.; Daly, N.L.; Mobli, M.; Morales, R.A.; King, G.F. Isolation of an orally active insecticidal toxin from the venom of an Australian tarantula. PLOS ONE 2013, 8, e73136. [CrossRef] [PubMed]

14. Mukherjee, A.K.; Sollod, B.L.; Wikel, S.K.; King, G.F. Orally active acaricidal peptide toxins from spider venom. Toxicon 2006, 47, 182-187. [CrossRef] [PubMed]

15. Khan, S.A.; Zafar, Y.; Briddon, R.W.; Malik, K.A.; Mukhtar, Z. Spider venom toxin protects plants from insect attack. Transgenic Res. 2006, 15, 349-357. [CrossRef] [PubMed]

16. Guo, S.; Herzig, V.; King, G.F. Dipteran toxicity assays for determining the oral insecticidal activity of venoms and toxins. Toxicon 2018, 150, 297-303. [CrossRef] [PubMed]

17. Clark, R.J.; Jensen, J.; Nevin, S.T.; Callaghan, B.P.; Adams, D.J.; Craik, D.J. The engineering of an orally active conotoxin for the treatment of neuropathic pain. Angew. Chem. Int. Ed. Engl. 2010, 49, 6545-6548. [CrossRef] [PubMed]

18. Clark, R.J.; Akcan, M.; Kaas, Q.; Daly, N.L.; Craik, D.J. Cyclization of conotoxins to improve their biopharmaceutical properties. Toxicon 2012, 59, 446-455. [CrossRef] [PubMed]

19. Muttenthaler, M.; Alewood, P.F. Selenopeptide chemistry. J. Pept. Sci. 2008, 14, 1223-1239. [CrossRef] [PubMed]

20. De Araujo, A.D.; Herzig, V.; Windley, M.J.; Dziemborowicz, S.; Mobli, M.; Nicholson, G.M.; Alewood, P.F.; King, G.F. Do vicinal disulfide bridges mediate functionally important redox transformations in proteins? Antioxid. Redox Signal. 2013, 19, 1976-1980. [CrossRef] [PubMed]

21. Mobli, M.; Morgenstern, D.; King, G.F.; Alewood, P.F.; Muttenthaler, M. Site-specific $\mathrm{pK}_{\mathrm{a}}$ determination of selenocysteine residues in selenovasopressin by using 77Se NMR spectroscopy. Angew. Chem. Int. Ed. 2011, 50, 11952-11955. [CrossRef] [PubMed]

22. Muttenthaler, M.; Andersson, A.; de Araujo, A.D.; Dekan, Z.; Lewis, R.J.; Alewood, P.F. Modulating oxytocin activity and plasma stability by disulfide bond engineering. J. Med. Chem. 2010, 53, 8585-8596. [CrossRef] [PubMed]

23. Craik, D.J. Protein folding: Turbo-charged crosslinking. Nat. Chem. 2012, 4, 600-602. [CrossRef] [PubMed]

24. De Araujo, A.D.; Callaghan, B.; Nevin, S.T.; Daly, N.L.; Craik, D.J.; Moretta, M.; Hopping, G.; Christie, M.J.; Adams, D.J.; Alewood, P.F. Total synthesis of the analgesic conotoxin MrVIB through selenocysteine-assisted folding. Angew. Chem. Int. Ed. 2011, 50, 6527-6529. [CrossRef] [PubMed]

25. Muttenthaler, M.; Nevin, S.T.; Grishin, A.A.; Ngo, S.T.; Choy, P.T.; Daly, N.L.; Hu, S.H.; Armishaw, C.J.; Wang, C.I.; Lewis, R.J.; et al. Solving the $\alpha$-conotoxin folding problem: Efficient selenium-directed on-resin generation of more potent and stable nicotinic acetylcholine receptor antagonists. J. Am. Chem. Soc. 2010, 132, 3514-3522. [CrossRef] [PubMed]

26. Steiner, A.M.; Woycechowsky, K.J.; Olivera, B.M.; Bulaj, G. Reagentless oxidative folding of disulfide-rich peptides catalyzed by an intramolecular diselenide. Angew. Chem. Int. Ed. 2012, 51, 5580-5584. [CrossRef] [PubMed]

27. Clark, R.J.; Fischer, H.; Dempster, L.; Daly, N.L.; Rosengren, K.J.; Nevin, S.T.; Meunier, F.A.; Adams, D.J.; Craik, D.J. Engineering stable peptide toxins by means of backbone cyclization: Stabilization of the

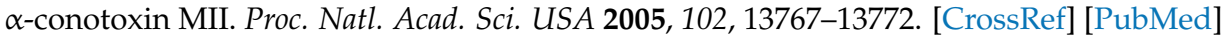

28. Lovelace, E.S.; Armishaw, C.J.; Colgrave, M.L.; Wahlstrom, M.E.; Alewood, P.F.; Daly, N.L.; Craik, D.J. Cyclic MrIA: A stable and potent cyclic conotoxin with a novel topological fold that targets the norepinephrine transporter. J. Med. Chem. 2006, 49, 6561-6568. [CrossRef] [PubMed] 
29. Halai, R.; Callaghan, B.; Daly, N.L.; Clark, R.J.; Adams, D.J.; Craik, D.J. Effects of cyclization on stability, structure, and activity of $\alpha$-conotoxin RgIA at the $\alpha 9 \alpha 10$ nicotinic acetylcholine receptor and $\mathrm{GABA}_{\mathrm{B}}$ receptor. J. Med. Chem. 2011, 54, 6984-6992. [CrossRef] [PubMed]

30. Wu, X.; Huang, Y.H.; Kaas, Q.; Harvey, P.J.; Wang, C.K.; Tae, H.S.; Adams, D.J.; Craik, D.J. Backbone cyclization of analgesic conotoxin GeXIVA facilitates direct folding of the ribbon isomer. J. Biol. Chem. 2017, 292, 17101-17112. [CrossRef] [PubMed]

31. Chong, Y.; Hayes, J.L.; Sollod, B.; Wen, S.; Wilson, D.T.; Hains, P.G.; Hodgson, W.C.; Broady, K.W.; King, G.F.; Nicholson, G.M. The $\omega$-atracotoxins: Selective blockers of insect M-LVA and HVA calcium channels. Biochem. Pharmacol. 2007, 74, 623-638. [CrossRef] [PubMed]

32. Herzig, V.; Bende, N.S.; Alam, M.S.; Tedford, H.W.; Kennedy, R.M.; King, G.F. Methods for deployment of spider-venom peptides as bioinsecticides. In Advances in Insect Physiology: Insect Midgut and Insecticidal Proteins for Insect Control; Dhadialla, T.S., Gill, S.S., Eds.; Academic Press: London, UK, 2014; Volume 7, pp. 389-411.

33. Kongsuwan, K.; Gough, J.; Kemp, D.; McDevitt, A.; Akhurst, R. Characterization of a new Bacillus thuringiensis endotoxin, Cry47Aa, from strains that are toxic to the Australian sheep blowfly, Lucilia cuprina. FEMS Microbiol. Lett. 2005, 252, 127-136. [CrossRef] [PubMed]

34. Bende, N.S.; Dziemborowicz, S.; Mobli, M.; Herzig, V.; Gilchrist, J.; Wagner, J.; Nicholson, G.M.; King, G.F.; Bosmans, F. A distinct sodium channel voltage-sensor locus determines the insect selectivity of the spider toxin Dc1a. Nat. Commun. 2014, 5, 4350. [CrossRef] [PubMed]

35. Undheim, E.A.; Grimm, L.L.; Low, C.F.; Morgenstern, D.; Herzig, V.; Zobel-Thropp, P.; Pineda, S.S.; Habib, R.; Dziemborowicz, S.; Fry, B.G.; et al. Weaponization of a hormone: Convergent recruitment of hyperglycemic hormone into the venom of arthropod predators. Structure 2015, 23, 1283-1292. [CrossRef] [PubMed]

36. Zlotkin, E.; Fishman, L.; Shapiro, J.P. Oral toxicity to flesh flies of a neurotoxic polypeptide. Arch. Insect Biochem. Physiol. 1992, 21, 41-52. [CrossRef] [PubMed]

37. Primor, N.; Teitelbaum, Z.; Zlotkin, E. Penetrability of orally toxic protein from cobra venom through the gut of a blowfly. Biochim. Biophys. Acta 1980, 627, 71-81. [CrossRef]

38. Bloomquist, J.R. Mode of action of atracotoxin at central and peripheral synapses of insects. Invertebr. Neurosci. 2003, 5, 45-50. [CrossRef] [PubMed]

39. Audsley, N.; Matthews, J.; Nachman, R.J.; Weaver, R.J. Transepithelial flux of an allatostatin and analogs across the anterior midgut of Manduca sexta larvae in vitro. Peptides 2008, 29, 286-294. [CrossRef] [PubMed]

40. Nachman, R.J.; Teal, P.E.; Strey, A. Enhanced oral availability/pheromonotropic activity of peptidase-resistant topical amphiphilic analogs of pyrokinin/PBAN insect neuropeptides. Peptides 2002, 23, 2035-2043. [CrossRef]

41. Habibi, J.; Brandt, S.L.; Coudron, T.A.; Wagner, R.M.; Wright, M.K.; Backus, E.A.; Huesing, J.E. Uptake, flow, and digestion of casein and green fluorescent protein in the digestive system of Lygus hesperus Knight. Arch. Insect Biochem. Physiol. 2002, 50, 62-74. [CrossRef] [PubMed]

42. Modespacher, U.P.; Rudin, W.; Jenni, L.; Hecker, H. Transport of peroxidase through the midgut epithelium of Glossina m. morsitans (Diptera, Glossinidae). Tissue Cell 1986, 18, 429-436. [CrossRef]

43. Zhu, W.; Vandingenen, A.; Huybrechts, R.; Vercammen, T.; Baggerman, G.; De Loof, A.; Poulos, C.P.; Velentza, A.; Breuer, M. Proteolytic breakdown of the Neb-trypsin modulating oostatic factor (Neb-TMOF) in the hemolymph of different insects and its gut epithelial transport. J. Insect Physiol. 2001, 47, 1235-1242. [CrossRef]

44. Schnolzer, M.; Alewood, P.; Jones, A.; Alewood, D.; Kent, S.B. In Situ neutralization in Boc-chemistry solid phase peptide synthesis. Rapid, high yield assembly of difficult sequences. Int. J. Pept. Protein Res. 1992, 40, 180-193. [CrossRef] [PubMed]

45. Muttenthaler, M.; Albericio, F.; Dawson, P.E. Methods, setup and safe handling for anhydrous hydrogen fluoride cleavage in Boc solid-phase peptide synthesis. Nat. Protoc. 2015, 10, 1067-1083. [CrossRef] [PubMed]

46. Dawson, P.E.; Muir, T.W.; Clark-Lewis, I.; Kent, S.B. Synthesis of proteins by native chemical ligation. Science 1994, 266, 776-779. [CrossRef] [PubMed]

47. Goddard, T.D.; Kneller, D.G. SPARKY3; University of California: San Francisco, CA, USA, 2001.

48. Vranken, W.F.; Boucher, W.; Stevens, T.J.; Fogh, R.H.; Pajon, A.; Llinas, M.; Ulrich, E.L.; Markley, J.L.; Ionides, J.; Laue, E.D. The CCPN data model for NMR spectroscopy: Development of a software pipeline. Proteins 2005, 59, 687-696. [CrossRef] [PubMed] 
49. Bende, N.S.; Kang, E.; Herzig, V.; Bosmans, F.; Nicholson, G.M.; Mobli, M.; King, G.F. The insecticidal neurotoxin Aps III is an atypical knottin peptide that potently blocks insect voltage-gated sodium channels. Biochem. Pharmacol. 2013, 85, 1542-1554. [CrossRef] [PubMed]

50. Herzig, V.; Hodgson, W.C. Neurotoxic and insecticidal properties of venom from the Australian theraphosid spider Selenotholus foelschei. Neurotoxicology 2008, 29, 471-475. [CrossRef] [PubMed]

51. Grolleau, F; Lapied, B. Two distinct low-voltage-activated $\mathrm{Ca}^{2+}$ currents contribute to the pacemaker mechanism in cockroach dorsal unpaired median neurons. J. Neurophysiol. 1996, 76, 963-976. [CrossRef] [PubMed]

52. Barry, P.H. JPCalc, a software package for calculating liquid junction potential corrections in patch-clamp, intracellular, epithelial and bilayer measurements and for correcting junction potential measurements. J. Neurosci. Methods 1994, 51, 107-116. [CrossRef]

53. Bezanilla, F.; Armstrong, C.M. Inactivation of the sodium channel. I. Sodium current experiments. J. Gen. Physiol. 1977, 70, 549-566. [CrossRef] [PubMed]

54. Wicher, D.; Penzlin, H. Ca ${ }^{2+}$ currents in central insect neurons: Electrophysiological and pharmacological properties. J. Neurophysiol. 1997, 77, 186-199. [CrossRef] [PubMed]

55. Zhou, W.; Goldin, A.L. Use-dependent potentiation of the Nav1.6 sodium channel. Biophys. J. 2004, 87, 3862-3872. [CrossRef] [PubMed]

56. Audsley, N.; Weaver, R.J.; Edwards, J.P. Enzyme linked immunosorbent assay for Manduca sexta allatostatin (Mas-AS), isolation and measurement of Mas-AS immunoreactive peptide in Lacanobia oleracea. Insect Biochem. Mol. Biol. 1998, 28, 775-784. [CrossRef]

(C) 2018 by the authors. Licensee MDPI, Basel, Switzerland. This article is an open access article distributed under the terms and conditions of the Creative Commons Attribution (CC BY) license (http://creativecommons.org/licenses/by/4.0/). 